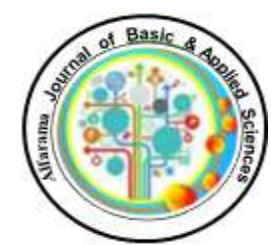

ISSN 2682-275X
Alfarama Journal of Basic \& Applied Sciences

Faculty of Science Port Said University

January 2021, Volume 2, Issue 1

Submitted: 06-08-2020

Accepted: $30-08-2020$ https://ajbas.journals.ekb.eg

ajbas@sci.psu.edu.eg

http://sci.psu.edu.eg/en/

DOI: $\underline{10.21608 / a j b a s .2020 .37520 .1028}$

\title{
A Comparative Study: Gene Expression VEGF, FLT-1and KDR And level of PLGF In Preeclampsia And Normal Pregnancy.
}

\author{
Ibrahim M. EL-Deen ${ }^{1}$, Amal K. Seleem ${ }^{2}$, A. A. Abdel Aziz ${ }^{3}$, E. H. ELSayd ${ }^{4}$, Ateya G. Amin ${ }^{5, *}$ \\ ${ }^{1}$ Department of Chemistry, Faculty of Science, Port Said University, Port Said, Egypt. \\ ${ }^{2}$ Department of Clinical Biochemistry, Faculty of Medicine, Mansoura University, Mansoura, Egypt. \\ ${ }^{3}$ Department of Gynocology, Faculty of Medicine, Mansoura University, Mansoura, Egypt. . \\ ${ }^{4}$ Department of Chemistry, Faculty of Science, Port Said University, Port Said, Egypt. \\ ${ }^{5}$ Insurance of health, Central laboratories, Mansoura, Egypt. \\ *Corresponding author: attiagomaa72@yahoo.com
}

\begin{abstract}
Involved The vascular endothelial growth factor (VEGF) family of angiogenic growth factors in the pathophysiology of these inconveniences . aims This study to examine Maternal serum levels of placental growth factor (PLGF) and Placental mRNA expression of VEGF, fms-like tyrosine kinase 1( FLT-1) and kinase insert domain receptor $(\mathrm{KDR})$ in normotensive control $(\mathrm{NC})$ women $(\mathrm{n}=24)$ and women with preeclampsia (PE) $(n=50)$ [25 severe PE (SPE) and 25 Mild PE (MPE)]. We conducted a cross-sectional study in 50 preeclamptic women: 25 women with mild PE, 25 patients with severe PE. While 24 normotensive pregnant women matched for age as a control group. we measured by real time PCR (RTPCR) Placental mRNA expression of VEGF FLT-1and KDR . and we measured Maternal serum levels of PLGF by ELISA. there was statistically significant difference between the three study groups as regards all 4 studied laboratory variables. KDR, FLT-1 and PLGF were all statistically significantly higher in control group as compared to either of the two PE groups. The mean VFGF expression was statistically higher in cases of severe PE than Mild PE, both were higher than control group $(\mathrm{p}<0.0005)$.
\end{abstract}

\section{Keywords}

Preeclampsia ; vascular endothelial growth factor ; fms-like tyrosine kinase 1; kinase insert domain receptor .

\section{INTRODUCTION}

Pre-eclampsia affects about $7 \%$ of all pregnancies, worldwide. It is a major cause of maternal morbidity and mortality and neonatal (1). Normally, during pregnancy, spiral arteries of uterus undergo a renovating by the intrusion of cytotrophoblast in their walls and in this way diminish an opposition in blood stream to intervillous spaces (2). Lacking invasion of trophoblast brings about placental ischemia and advancement of 
hypertension(3). FLT1 is expressed VEGFA and PIGF and KDR and in villous and extravillous trophoblasts, the vascular endothelium excess as well as increased natural killer cells known to change the level of expression in PE (4). It is suggested that disturbed placental angiogenesis is the main characteristic of causing preeclampsia. angiogenesis formation process begins with various angiogenic factors such as vascular endothelial growth factor (VEGF) and placental growth factor (PlGF) along with receptors associated with the membrane (5). Mechanisms that promote formation angiogenesis and vascular reformation in uteroplacental unit is not fully understood . as seen many of the molecular pathways as the placenta linked to defects such as PE; it is known that the angiogenic mediated VEGF family plays a key role path (6). Current data indicates that placental ischemia\& trophoblastic hypoprefusion with endothelial dysfunction as the most consistent change So far, There are many theories pathophysiological of gene expression in PE except for the decryption complete with many Muslim available to explain the different results obtained. In this way, we consider that it is useful to carry out our study using a control typical in situations in a different society to add a guide to the existing literature, Placental VEGF,KDR andFlt-1 mRNA levels have been reported to be decreased, increased or unchanged in PE cases versus uncomplicated controls. So, we undertook this study to determine the level of PLGF in maternal serum and expressions of VEGF,KDRandFlt-1 mRNA in placentae of PE in order to clarify the various discrepancies and gain further evidence for its role in Preeclampsia.

\section{PATIENT AND METHODS}

\subsection{Patients}

Fifty patients determined to have Preeclampsia were gathered from the Obstetrics and Gynecology division, Mansoura University, Egypt (Their mean age (years) \pm SD were $28.15 \pm 5.25$ ) during the period from July 2015 and May 2017.Preeclamptic women were partitioned into 25 women analyzed as mild preeclampsia (MPE), diagnosed as blood pressure $\geq 140 / 90 \mathrm{mmHg}$ and 25 women were analyzed as severe preeclampsia (SPE), diagnosed as blood pressure $\geq 160 / 110 \mathrm{mmHg}$. The control group included 24 normotensive pregnant women The blood tests were taken from all participants during pre-birth visits at second trimester between 20 to 24 gestational weeks. Maternal ages, weights, and height, gravidity, systolic and diastolic blood pressure, were recorded. Exclusion criteria included twin pregnancy, Women with a background marked by diabetes; thyroid, liver, or chronic renal disease; or preexisting chronic hypertension (defined as blood pressure $>140 / 90 \mathrm{mmHg}$ or need for antihypertensive medications before pregnancy or before $20 \mathrm{wk}$ gestation) also if they had a pregnancy termination, a major anomaly all these cases were excluded or if the pregnancy outcome was unknown (i.e. if they did not deliver at our hospital).Inclusion Criteria: Normotensive pregnant women had blood pressure less than 120/80 mm Hg and there was no history of high blood pressure or proteinuria. All pregnant women showed gestational age from 20 to 40 weeks, Control group were taken from women who entered Mansoura University Hospital, Egypt, Obstetric department, Maternal Study cohort within 2wk of each case. Ethical approval: A composed educated assent was taken before test withdrawal. The examination was acted as per the moral guidelines set down in Mansoura Faculty of Medicine.

\subsection{Methods}

\subsubsection{PIGF ELISA}

It was withdrawn $3 \mathrm{ml}$ of venous blood samples and left to clot between $15^{\circ} \mathrm{C}$ and $22{ }^{\circ} \mathrm{C}$ for 30 to 90 minutes. Then were centrifuged for them for 15 minutes at $300 \mathrm{~g}$. Serum was isolated, collected and stored at $-20^{\circ} \mathrm{C}$ until the time of measure for PIGF (human placenta growth factor (, PlGF ELISA Kit / SAB Catalog No: EK1302) Sun Red (Biotechnology Company). Shanghai. 


\subsubsection{Urine Collection:}

For pregnant ladies. Was required to ten $\mathrm{ml}$ of urine to detect the protein by dipstick measurement in two samples random at least were randomized to get ahead of them at least 4 hours. Protein means the protein $\geq 3$ g. In 24 hours (medi-test combi \& Co. KG, Germany).

\subsubsection{RNA extraction from placental tissue}

Were performed Fresh samples of 74 placentas humanity within 30 minutes after birth of the placenta, and after washing the samples with normal saline, removed layers amniotic and decidua motherly, then freeze samples in liquid nitrogen and stored at $-70^{\circ} \mathrm{C}$ until the displacement of the RNA using miRNeasy mini kit (Qiagen, cat No. 217 004, Germany). RNA was quantified by spectrophotometry(7).

we measured the expression of VEGF, FLT-1 and KDR genes in placenta by used TaqMan real-time PCR (provided by Thermo Scientific, USA, cat No. \# K1641).

\subsubsection{Reverse transcription of RNA extracted for the production of DNA}

For each sample, was used $1 \mu \mathrm{g}$ of total RNA Adjust by reverse transcription using the Maxima ${ }^{\circledR}$ First Strand cDNA synthess kit provided by Thermo Scientific, USA, cat. No.K1641. Following the manufacturer's instructions, Reverse transcription and the quantitative PCR were performed as previously described $(8,9)$., Genetic prefixes own purchased from Invitrogen by Thermo Fisher Scientific. It was selected primer sets to amplify the gene PCR after three of the gene sequence database NCBI (10). It included the following assay targeting specific mRNAs in the study:.

\section{VEGF:}

\section{Forward: 5 -GGGGGCAGAATCATCACGAA-3, Reverse: 5CCAGGGTCTCGATTGGATGG-3 .}

Flt1:

Forward: 5-CTGCAAGATTCAGGCACCTATG-3, Reverse: 5-GTTTCGCAGGAGGTATGGTGCT-3.

KDR:

Forward: 5-GTAGGACTGCTCAGTTCAAACAT-3,Revers 5- ACAGTTACTACACCCGTAAG-3.

\subsubsection{Quantitative PCR Analysis (11)}

PCR was performed in real-time serial to estimate the quantification of genes VEGF and Flt1 and KDR using SensiFAST SYBR® Lo-ROX (purchased from Bioline, London, United Kingdom, Catalog Number: BIO-94005) following the manufacturer's instructions. Analysis was performed fusion curve after amplification to confirm the product's privacy and exclude the presence Altmhedy- dimmers. Genetic expression was performed using the relative delta delta cycle threshold (DDCT)by using method $2-\Delta \Delta \mathrm{ct}$. The relative gene expression analysis was done by Delta Delta cycle threshold (DDCT) method, and the average DCT of the healthy volunteers for each target gene was used as the calibrator sample $(14,15)$. The amount of target, normalized to an endogenous reference and relative to a calibrator, was calculated. The fold change is obtained by $2-$ DDCT. This method assigns a value of 0.7 to the calibrator sample, and all other quantities are expressed as an $\mathrm{n}$-fold difference relative to the calibrator.

\section{STATISTICAL ANALYSES}

Data analysis was performed by Statistical package for social science software (SPSS) version 25. Data are presented as mean \pm SD and compared by One-Way ANOVA and they are presented as median (IQR) and compared by Kruskal-Wallis (K-W) test. Significance was considered at p value less than 0.05 . $*$ Data are presented as frequency (percentage) and compared by Chi-Square test (Monte Carlo significance).

**Data are presented as median (IQR) and compared by Kruskal-Wallis (K-W) test. Pairwise comparisons are presented as capital letters (similar letters $=$ no significant difference, while different letters $=$ significant difference). 


\section{DISCUSSION AND RESULTS}

This study involved 74 subjects divided into 3 groups: The first is control group: 24 pregnant ladies with no current or previous pre-eclampsia. Their mean age (years) $\pm \mathrm{SD}=27.8 \pm 4.7$ years. The second is mild preeclampsia group: 25 pregnant ladies fulfilling the criteria of mild pre-eclampsia. Their mean age $\pm \mathrm{SD}$ were $27.5 \pm 4.3$ years. The third is severe pre-eclampsia group: 25 pregnant women fulfilling the criteria of severe pre-eclampsia. Their mean age (years) $\pm \mathrm{SD}=28.8 \pm 6.2$ years. (figure 1and Table 1) ; It showed that a statistically significant difference existed for the other variables; systolic blood pressure (SBP), Diastolic blood pressure (DBP) and Mean average pressuren( MAP), they all were statistically significantly higher in severe PE > Mild PE > Control. There are statistically significant differences in the level of protein in the urine with trace and + in mild cases, but ++ and +++ in severe cases $(\mathrm{P}<0.0005)$ (figure 2$)$.

This study contains many interesting results and new that will help in the understanding of the expression pattern of angiogenic and anti angiogenic factors in the placenta. figure (3) that there are statistically significant differences between the study groups with respect to the three variable studied laboratory.VFGF was statistically significantly higher in severe PE > Mild PE > Control.

VEGF expression of receptors in the discussion of the placenta, there is a contradiction in the large literature on levels of VEGF placenta in cases of pregnancy PE $(14,15)$. In 2011, Paiva and colleagues worked on both maternal blood and placental tissue in preeclampsia and found correlation of gene expression between the two (16). mRNA expressions were, highly expressed in preeclampsia, however it have been studied in maternal blood samples by a few others $(17,18,19)$.

Table (1): Comparison of the clinical variables between the three study groups

\begin{tabular}{|c|c|c|c|c|c|}
\hline \multirow{2}{*}{ Variable } & \multicolumn{3}{|l|}{ Group } & \multirow[b]{2}{*}{ Statistic } & \multirow[b]{2}{*}{$P$ value } \\
\hline & $\begin{array}{l}\text { Control } \\
(n=24)\end{array}$ & $\begin{array}{l}\text { Mild PE } \\
(n=25)\end{array}$ & $\begin{array}{l}\text { Severe PE } \\
(n=25)\end{array}$ & & \\
\hline Age (years) & $27.8 \pm 4.7$ & $27.5 \pm 4.3$ & $28.8 \pm 6.2$ & $\mathrm{~F}=0.459$ & $* 0.634$ \\
\hline $\mathrm{SBP}(\mathrm{mmHg})$ & $\begin{array}{l}115(110-120) \\
\text { A }\end{array}$ & $\begin{array}{l}140(135-140) \\
\text { B }\end{array}$ & $\begin{array}{l}170(165-172.5) \\
C\end{array}$ & $\mathrm{~K}-\mathrm{W}=61.02$ & $* * *<0.0005$ \\
\hline $\begin{array}{l}\text { DBP } \\
(\mathrm{mmHg})\end{array}$ & $\begin{array}{l}75(75-80) \\
\text { A }\end{array}$ & $\begin{array}{l}85(80-90) \\
\text { B }\end{array}$ & $\begin{array}{l}110(107.5-115) \\
C\end{array}$ & $\mathrm{~K}-\mathrm{W}=61.66$ & $* * *<0.0005$ \\
\hline $\begin{array}{l}\text { MAP } \\
(\mathrm{mmHg})\end{array}$ & $\begin{array}{l}90(86.6-91.7) \\
\mathrm{A}\end{array}$ & $\begin{array}{l}103(99.1-105.8) \\
\text { B }\end{array}$ & $\begin{array}{l}130(126.6-134) \\
C\end{array}$ & $\mathrm{~K}-\mathrm{W}=64.24$ & $* * *<0.0005$ \\
\hline
\end{tabular}

*Data are presented as mean \pm SD and compared by One-Way ANOVA. **Data are presented as frequency (percentage) and compared by Chi-Square test (Monte Carlo significance). ***Data are presented as median (IQR) and compared by Kruskal-Wallis (K-W) test. Pairwise comparisons are presented as capital letters ( similar letters $=$ no significant difference, while different letters $=$ significant difference $)$.

It supports the current results the results of a number of studies that have announced increased expression of VEGF in pre-eclampsia (20-21). On the contrary, some studies have shown reduced expression of VEGF expression in placental tissues of preeclampsia(22). Kim et al. and Bates, revealed that, expression of the low expressions of VEGF in both the level of mRNA and protein in the tissues of the placenta in the third trimester of pregnancy for patients with PE $(n=20)$ compared with an equal number of standard controls $(\mathrm{p}<0.05)(22-23)$. In addition, some studies revealed an expression of VEGF is variable in the tissues of the placenta in women PE $(6,7)$. 


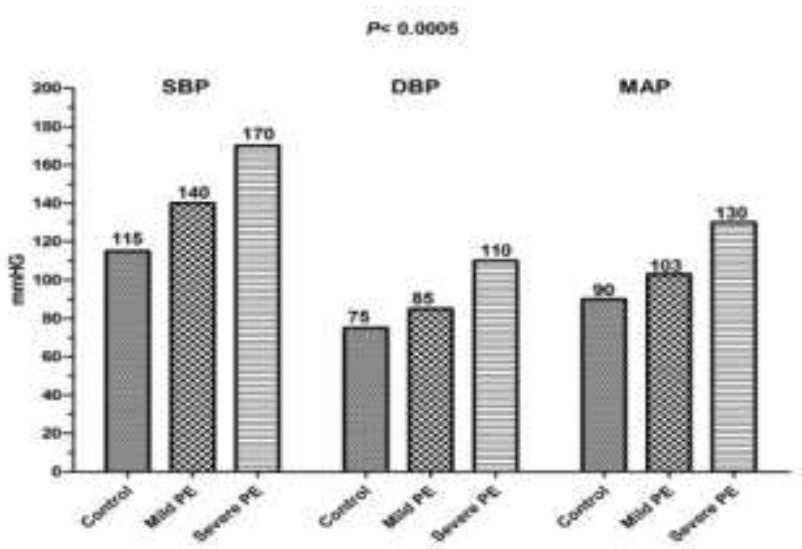

Fig 1: Comparison of SBP, DBP and MAP between the three study groups

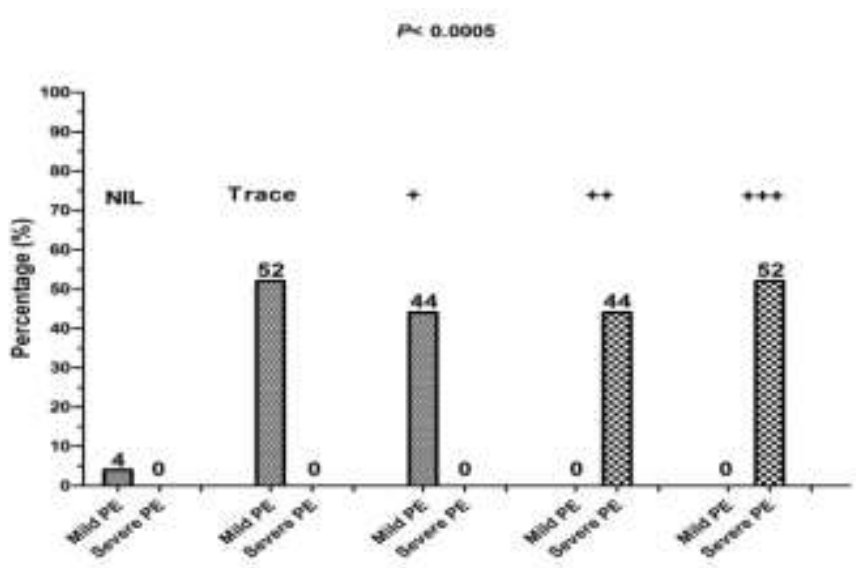

Fig 2: Comparison of proteinuria between mild and severe PE groups.

The results of the discrepancy may be observed between these studies because of the phenotypic classification of PE chosen ,the variations in sample size, the timing of taking placenta tissue samples, the method of measuring the amount of VEGF, Imaging results and references taken for comparison. There are many genetic and environmental factors that may change for pre-eclampsia gene expression. Also, the pathophysiology of the expression of VEGF in the remote PE to decode the full encryption code with many of the assumptions available to explain the different results obtained (21). The present study showed that, PLGF maternal serum level was statistically significantly higher in control group as compared to either of the two PE groups $(\mathrm{p}<0.0005)$ and there is no statistically significantly difference between $\mathrm{sPE}$ and $\mathrm{mPE}$ (figure 4) . Low level of PIGF than normal due to the lack of re-formation of blood vessels of the arteries of the spiral ultimately leads to increased ischemia of the placenta, which may be involved in the following adverse pregnancy outcomes: SGA, PE, HELLP (hemolysis, increased liver enzymes, low platelets) ( syndrome) $15,24,25)$. Our study correspond with many of the studies that have shown that the level of PlGF low in complex pregnancies due to $\mathrm{PE}(26,27,28)$.

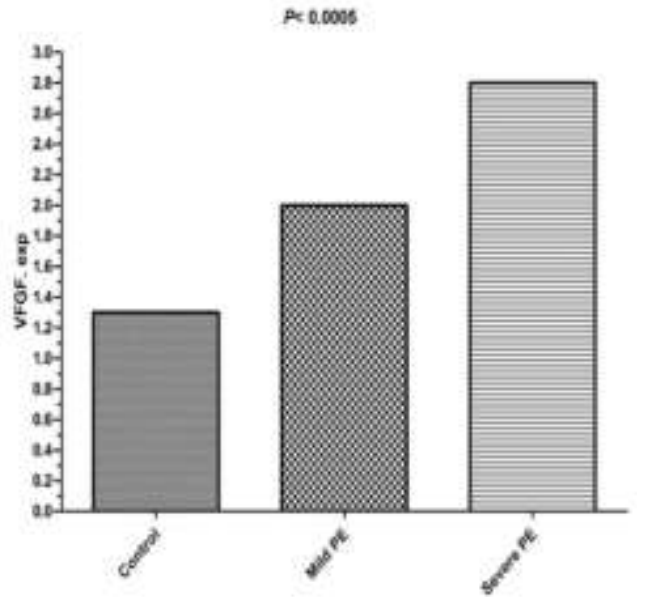

Fig 3: Comparison of VFGF gene expression Between the three study groups .

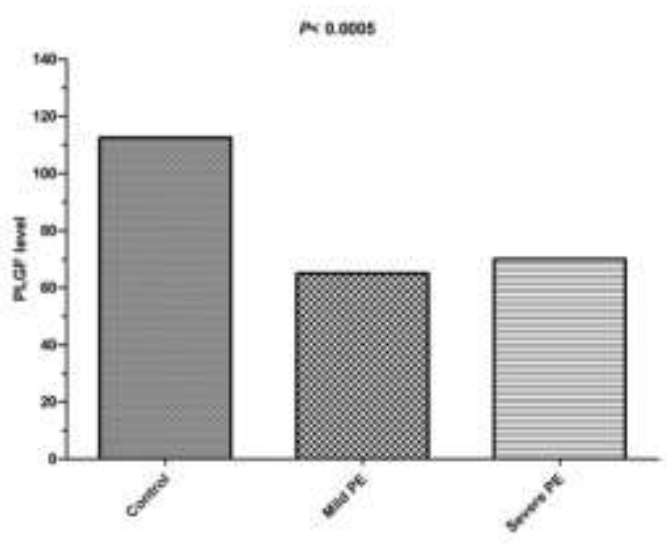

Fig 4: Comparison of PLGF level between the three study groups.

Differential expression of VEGF receptors in PE is recorded in various past examinations, with a couple of discoveries of an expansion in both VEGFR-1 and VEGFR-2 expression $(29,30,31)$ and others revealing 
no distinction in VEGFR2 $(37,29,31)$. This study presented a significant reduction in both the expression of VEGFR-1 and VEGFR-2 (P <0.01) in PE contrasted to the control group.

(figures 5 and 6), which is consistent with a previous study $(6,32,21,33)$, and in serum concentration VEGFR2 (34,35).

Inadequate placentation in PE prompts hypoxia, one of the variables known to decrease VEGFR-2 expression in the endothelial cells. Besides, the low oxygen likewise prompts expanded circling sFlt-1, a splice variant of VEGFR-1 which does not have the transmembrane and cytoplasmic areas. sFlt-1 antagonizes the proangiogenic effects of both VEGF and PIGF by binding and in this manner forestalling collaboration with their receptors (18).,Moreover, a negative connection with an expansion in sFlt-1 and decrease in VEGFR-2 expression in the PE bunch is as per a past report by Nevo et al., sFlt-1 is known to tie VEGF prompting diminished accessibility of VEGF(38).Diminished accessibility of free VEGF may have brought about diminished VEGFR-2 mRNA expression in PE as free VEGF stimulates VEGFR-2 synthesis alongside its dealing at the outside of endothelial cells(36).

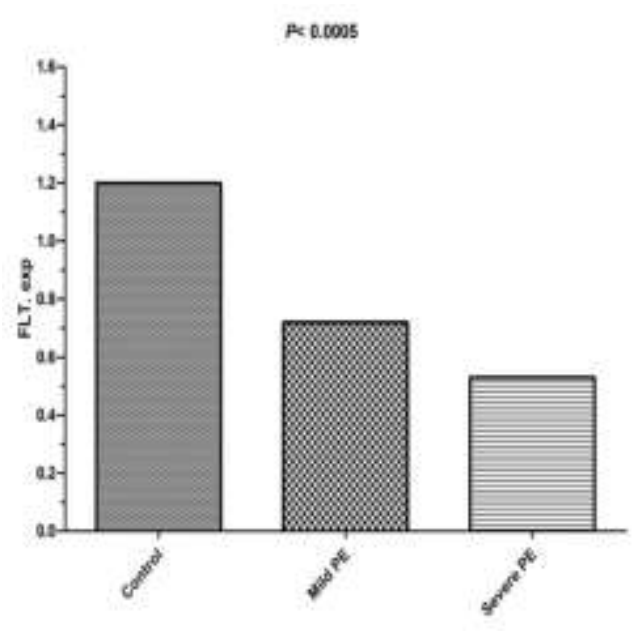

Fig. 5: Compared FLT-1 gene expression between the three study groups

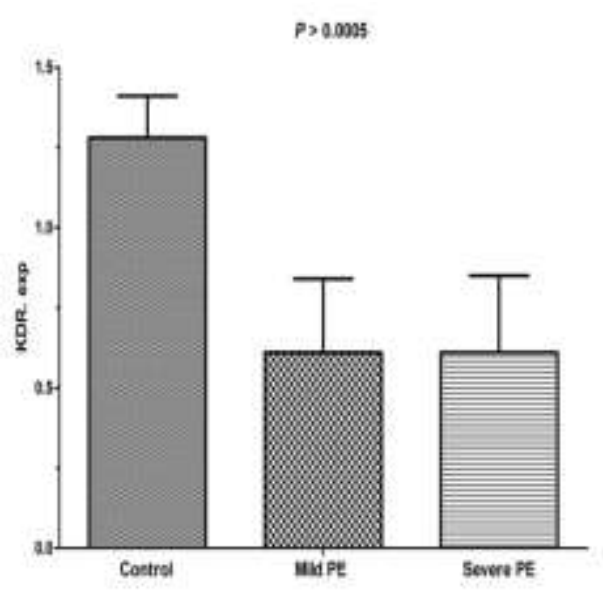

Fig. 6: Compared KDR gene expression between between the three study groups

*Data are presented as mean \pm SD and compared by One-Way ANOVA. **Data are presented as frequency (percentage) and compared by Chi-Square test (Monte Carlo significance).

***Data arepresented as median (IQR) and compared by Kruskal-Wallis (K-W) test. Pairwise comparisons are presented as capital letters (similar letters $=$ no significant difference, while different letters $=$ significant difference).

\section{CONCLUSION}

Vascular and angiogenesis factors are helpful in reducing pre-eclampsia in women with risk factors and early discovery of pre-eclampsia for diagnosis and anticipating the improvement of complications accurately. There is a need for more studies to understand the molecular defect in the pre-eclampsia and the role of the vital signs of the composition of these angiogenic biomarkers to diagnose the condition of obstetric and predictable treatment. 


\section{AKNOWLEDGEMENT}

We thank all our subjects and technical staff of the hospital for their cooperation.

\section{REFERENCES}

[1] DULEY, L. The global impact of pre-eclampsia and eclampsia. In: Seminars in perinatology. pp. 130-137 Elsevier (2009).

[2] KAM, E. P. Y. ET AL. The role of trophoblast in the physiological change in decidual spiral arteries. Hum. Reprod., 14, 8, 2131-2138, 1999.

[3] PAPAGEORGHIOU, A. T. ET AL. The role of uterine artery Doppler in predicting adverse pregnancy outcome. Best Pract. Res. Clin. Obstet. Gynaecol., 18, 3, 383-396 , 2004.

[4] TANDON, V. ET AL. Assessment of serum vascular endothelial growth factor levels in pregnancy induced hypertension patients. J. Pregnancy., 2017, , 2017.

[5] DEMIR, R. ET AL. Vasculogenesis and angiogenesis in the endometrium during menstrual cycle and implantation. Acta Histochem., 112, 3, 203-214 , 2010.

[6] ANDRAWEERA, P. H. ET AL. Placental expression of VEGF family mRNA in adverse pregnancy outcomes. Placenta., 33, 6, 467-472, 2012.

[7] MACFARLANE, D. E. AND DAHLE, C. E. Isolating RNA from whole blood-the dawn of RNAbased diagnosis? Nature., 362, 6416, 186-188, 1993.

[8] SAMBROOK, H. C. Molecular cloning: a laboratory manual. Cold Spring Harbor, NY. , 1989.

[9] FREEMAN, W. M. ET AL. Quantitative RT-PCR: pitfalls and potential. Biotechniques., 26, 1, 112-125, 1999.

[10] SAIKI, R. K. ET AL. Primer-directed enzymatic amplification of DNA with a thermostable DNA polymerase. Science (80-. )., 239, 4839, 487-491 , 1988.

[11] YE, J. ET AL. Primer-BLAST: a tool to design target-specific primers for polymerase chain reaction. BMC Bioinformatics., 13, 1, 134 , 2012.

[12] HIGUCHI, R. ET AL. Kinetic PCR analysis: real-time monitoring of DNA amplification reactions. Bio/technology., 11, 9, 1026-1030, 1993.

[13] LIVAK, K. J. AND SCHMITTGEN, T. D. Analysis of relative gene expression data using real-time quantitative PCR and the 2- $\Delta \Delta \mathrm{CT}$ method. methods., 25, 4, 402-408 , 2001.

[14] STAFF, A. C. ET AL. Redefining preeclampsia using placenta-derived biomarkers. Hypertension., 61, 5, 932-942, 2013.

[15] JIM, B. AND KARUMANCHI, S. A. Preeclampsia: pathogenesis, prevention, and long-term complications. In: Seminars in nephrology. pp. 386-397 Elsevier (2017).

[16] PAIVA, P. ET AL. Measurement of mRNA transcripts of very high placental expression in maternal blood as biomarkers of preeclampsia. J. Clin. Endocrinol. Metab., 96, 11, E1807-E1815 , 2011.

[17] FARINA, A. ET AL. Performance of messenger RNAs circulating in maternal blood in the prediction of preeclampsia at 10-14 weeks. Am. J. Obstet. Gynecol., 203, 6, 575-e1 , 2010.

[18] OKAZAKI, S. ET AL. Placenta-derived, cellular messenger RNA expression in the maternal blood of preeclamptic women. Obstet. Gynecol., 110, 5, 1130-1136, 2007.

[19] REN, Y. ET AL. Vascular endothelial growth factor expression in peripheral blood of patients with pregnancy induced hypertension syndrome and its clinical significance. Pakistan J. Med. Sci., 30, 3, $634,2014$.

[20] DEEPALI, P. ET AL. Differential placental methylation and expression of VEGF, FLT-1 and KDR genes in human term and preterm preeclampsia. Clinical Epigenetics. , 5:6.doi:10.1186/1868-7083$5-6,2013$. 
[21] AGARWAL, R. ET AL. Evaluation of Placental VEGFA mRNA Expression in Preeclampsia: A Case Control Study. J. Obstet. Gynecol. India., 69, 2, 142-148 , 2019.

[22] KIM, J. Y. ET AL. The expression of VEGF receptor genes is concurrently influenced by epigenetic gene silencing of the genes and VEGF activation. Epigenetics., 4, 5, 313-321 , 2009.

[23] BATES, D. O. An unexpected tail of VEGF and PIGF in pre-eclampsia, (2011).

[24] SIBAI, B. ET AL. Pre-eclampsia. Lancet., 365, 9461, 785-799 , 2005.

[25] MIHU, D. ET AL. HELLP syndrome-a multisystemic disorder. J. Gastrointest. Liver Dis., 16, 4, $419,2007$.

[26] SIBAI, B. M. ET AL. Serum inhibin A and angiogenic factor levels in pregnancies with previous preeclampsia and/or chronic hypertension: are they useful markers for prediction of subsequent preeclampsia? Am. J. Obstet. Gynecol., 199, 3, 268-e1 , 2008.

[27] VATTEN, L. J. ET AL. Changes in circulating level of angiogenic factors from the first to second trimester as predictors of preeclampsia. Am. J. Obstet. Gynecol., 196, 3, 239-e1 , 2007.

[28] SUNG, K. U. ET AL. Maternal serum placental growth factor and pregnancy-associated plasma protein A measured in the first trimester as parameters of subsequent pre-eclampsia and small-forgestational-age infants: A prospective observational study. Obstet. Gynecol. Sci., 60, 2, 154-162 , 2017.

[29] CHUNG, J.-Y. ET AL. Differential expression of vascular endothelial growth factor (VEGF), endocrine gland derived-VEGF, and VEGF receptors in human placentas from normal and preeclamptic pregnancies. J. Clin. Endocrinol. Metab., 89, 5, 2484-2490 , 2004.

[30] TOFT, J. H. ET AL. Whole-genome microarray and targeted analysis of angiogenesis-regulating gene expression (ENG, FLT1, VEGF, PIGF) in placentas from pre-eclamptic and small-forgestational-age pregnancies. J. Matern. Neonatal Med., 21, 4, 267-273 , 2008.

[31] ESCUDERO, C. ET AL. Increased placental angiogenesis in late and early onset pre-eclampsia is associated with differential activation of vascular endothelial growth factor receptor 2. Placenta., 35 , 3, 207-215, 2014.

[32] ALI, Z. ET AL. Comparative gene expression analysis of Fas and related genes in preeclamptic and healthy women: A cross-sectional study. Int. J. Reprod. Biomed., 18, 4, 235 , 2020.

[33] GROTEN, T. ET AL. Differential expression of VE-cadherin and VEGFR2 in placental syncytiotrophoblast during preeclampsia-New perspectives to explain the pathophysiology. Placenta., 31, 4, 339-343, 2010.

[34] PANT, V. ET AL. A cross sectional study to assess the sFlt-1: PlGF ratio in pregnant women with and without preeclampsia. BMC Pregnancy Childbirth., 19, 1, 266 , 2019.

[35] SAHAY, A. S. ET AL. A longitudinal study of circulating angiogenic and antiangiogenic factors and AT1-AA levels in preeclampsia. Hypertens. Res., 37, 8, 753-758, 2014.

[36] MUNAUT, C. ET AL. Differential expression of Vegfr-2 and its soluble form in preeclampsia. PLoS One., 7, 3, e33475, 2012.

[37] TSATSARIS, V. ET AL. Overexpression of the soluble vascular endothelial growth factor receptor in preeclamptic patients: pathophysiological consequences. J. Clin. Endocrinol. Metab., 88, 11, 5555-5563, 2003.

[38] NEVO, O. ET AL. Attenuation of VEGFR-2 expression by sFlt-1 and low oxygen in human placenta. PLoS One., 8, 11, e81176, 2013. 